\title{
Factores ambientales relacionados con la presentación de virus influenza A en aves silvestres
}

\author{
Soledad Ruiz P1,2 $₫\left(\mathbb{0}\right.$ M.Sc; Cecilia Baumberqer ${ }^{1,2} \otimes(\mathbb{0})$ M.Sc; Pedro Jimenez-Bluhm ${ }^{1} \otimes(\mathbb{0}$ Ph.D;

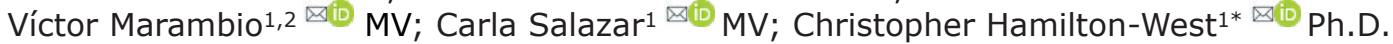

\begin{abstract}
${ }^{1}$ Universidad de Chile, Facultad de Ciencias Veterinarias y Pecuarias, Departamento de Medicina Preventiva animal, Unidad de Epidemiología. Av. Santa Rosa, 11735, La Pintana, Santiago, Chile.

2Universidad de Chile, Programa de Doctorado en Ciencias Silvoagropecuarias y Veterinarias, Campus Sur, Santiago, Chile.

*Correspondencia: christopher.hamilton@veterinaria.uchile.cl
\end{abstract}

Recibido: Noviembre 2019; Aceptado: Abril 2020; Publicado: Junio 2020.

\section{RESUMEN}

La investigación y el interés por el virus influenza aviar han aumentado considerablemente en las últimas décadas en respuesta a los brotes de influenza aviar de alta patogenicidad en aves de corral y a su potencial zoonótico. Las aves silvestres acuáticas son el principal reservorio del virus en la naturaleza, por lo tanto, la comprensión de la dinámica de infección del virus influenza A (VIA) en estas poblaciones es fundamental para entender su potencial de persistencia en el ambiente y sus posibilidades de transmisión hacia aves domésticas y humanos. Se ha identificado que factores ambientales (como temperatura, precipitaciones, vegetación y características del paisaje, entre otros) pueden tener un importante rol en el mantenimiento y diseminación del virus en las zonas de concentración de aves silvestres. Sin embargo, los estudios que incluyen aspectos ecológicos del virus y que exploran la interacción entre la prevalencia del VIA en aves silvestres y el ambiente, continúan siendo escasos. En esta revisión se resumen los esfuerzos de investigación que se han realizado para identificar a los factores ambientales involucrados en la persistencia y transmisión del VIA en lugares de concentración de aves silvestres y cómo estos factores pueden incidir en la prevalencia del virus en estas poblaciones, generando diferencias en la presentación de la infección entre distintas zonas geográficas.

Palabras clave: Orthomyxovirus, enfermedad de las aves, medio ambiente (Fuente: MeSh).

\section{ABSTRACT}

Research and interest in avian influenza virus have increased considerably in recent decades in response to highly pathogenic avian influenza outbreaks in poultry and its zoonotic potential. Wild waterfowl are the main reservoir of the virus, therefore studying the dynamics of influenza $A$ virus (IAV) infection in these populations is essential in order to understand its potential persistence in the environment and transmission to poultry and humans. It has been identified that environmental

Como citar (Vancouver).

Ruiz PS, Baumberger C, Jimenez-Bluhm P, Marambio V, Salazar C, Hamilton-West C. Factores ambientales relacionados con la presentación de virus influenza A en aves silvestes. Rev MVZ Córdoba. 2020; 25(2):e1845. https://doi.org/10.21897/rmvz.1845 
factors (such as temperature, rainfall, vegetation and landscape characteristics, among others) can play an important role in the maintenance and dissemination of the virus in the areas of concentration of wild birds. However, studies that include ecological aspects of the virus and explore the interaction between the prevalence of IAV in wild birds and environmental factors remain scarce. This review summarizes research efforts that have been made to identify the environmental factors involved in the persistence and transmission of IAV in areas of wild bird concentration and how these factors may influence the prevalence of the virus in these populations, generating differences in the presentation of the infection among different geographical areas.

Keywords: Orthomyxovirus, bird disease, environment (Source: MeSh).

\section{INTRODUCCIÓN}

El virus influenza es considerado mundialmente una amenaza tanto para la salud animal como para la salud pública, siendo el responsable de las cuatro pandemias humanas más grandes de los últimos cien años (1): "La Influenza Española" (1918), una de las pandemias más destructivas de la humanidad producida por un subtipo viral H1N1, "La Influenza Asiática" (1957) causada por un subtipo H2N2; "La Influenza de Hong Kong" provocada por un subtipo viral H3N2 y "La Influenza pandémica del año 2009", que surgió a partir de un subtipo H1N1 conformado por una combinación de genes de tres cepas diferentes (virus aviar H1N1, virus humano estacional H3N2 y virus porcino H1N1 de Norte América y Asia)(2).
Desde que comienza la epidemia del virus de la influenza aviar altamente patógena (IAAP) en el año 1997 causada por el subtipo H5N1 en Hong Kong, se han visto afectados más de 60 países pertenecientes a los 5 continentes (Figura 1). Asimismo, el número de cepas informadas a nivel mundial ha aumentado en forma alarmante, reconociéndose en los últimos años la emergencia de las nuevas variantes de IAAP H5N8 en el este de Asia y Europa, el subtipo H5N6 en Asia y la introducción de un virus H5Nx de origen Eurasiático en América del Norte, todos pertenecientes al nuevo clado 2.3.4.4 (3). Además, la aparición de nuevos subtipos que afectan a humanos (como el H1N1 pandémico y el H7N9 de origen aviar introducido a la población humana en Asia), ponen de manifiesto la necesidad de abordar esta enfermedad desde un enfoque global, comprendiendo los factores ecológicos y ambientales que afectan las interacciones hospedero-patógeno y que pueden influir en los patrones de presentación del virus.

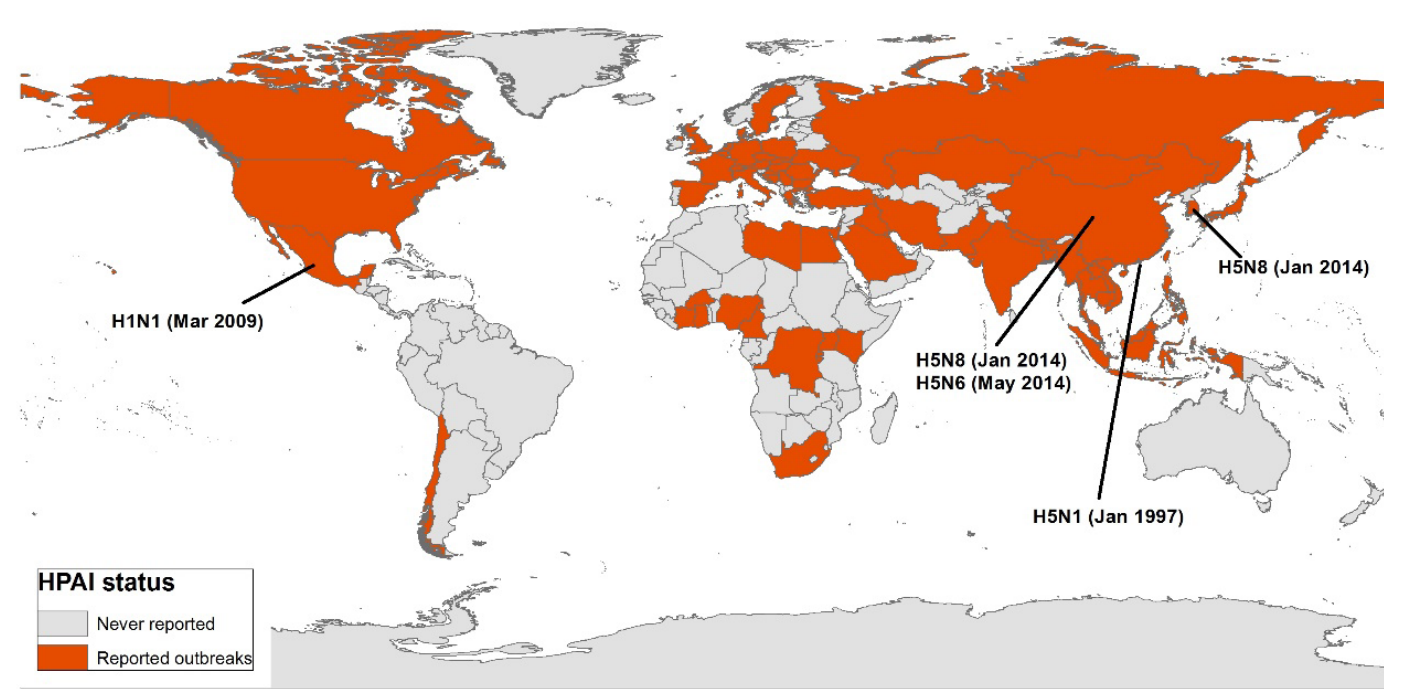

Figura 1.Países afectados por el virus de la influenza aviar altamente patógena (IAAP) desde 1997 hasta la fecha y lugares de emergencia de los principales subtipos de virus influenza $A$. 
El virus influenza se clasifica en dos grupos de acuerdo a su capacidad para producir o no enfermedad de gravedad en aves domésticas. Los virus IAAP presentan sitios de clivaje multibásico, replicándose en múltiples tejidos causando infección sistémica y alta mortalidad. Hasta el momento solo se han asociado los subtipos $\mathrm{H} 5$ y $\mathrm{H} 7$ a cuadros de alta patogenicidad. En cambio, los virus de influenza aviar de baja patogenicidad (IABP) presentan un sitio de clivaje monobásico, por lo tanto, frente a replicación se encuentran restringidos a los tejidos respiratorio y gastrointestinal, causando una enfermedad leve. Sin embargo, se describe que las cepas de IABP pueden mutar a una cepa de IAAP después de un tiempo de circulación en poblaciones de aves de corral, causando una enfermedad severa con alta mortalidad y morbilidad (4).

Las aves silvestres acuáticas tienen un papel clave en la ecología del VIA, ya que se reconocen como reservorios naturales de la mayoría de los subtipos descritos en la forma de IABP (5), teniendo el potencial de diseminarlo cuando estas migran dentro y entre continentes, representando un riesgo para la emergencia de brotes de IAAP en aves domésticas (6). Por lo tanto, la epidemiología de los VIA, su prevalencia y diversidad, estarían estrechamente relacionadas con el comportamiento de estas especies reservorios, incluyendo sus conductas de alimentación, hábitats y patrones migratorios, entre otros (7). Asimismo, existen además factores ambientales, como temperatura, precipitaciones, cantidad de vegetación y características propias del agua, que pueden favorecer el mantenimiento y diseminación del virus en zonas de concentración de aves silvestres $(8,9,10,11)$.

A pesar de lo anterior, son muy escasos los estudios que investiguen los factores ecológicos y ambientales que pueden condicionar la prevalencia del virus influenza en las aves silvestres. Los hallazgos encontrados hasta el momento corresponden a estudios que han sido realizados principalmente en el hemisferio norte (12-15) y en algunas regiones de África $(11,16,17)$.

La presente revisión tiene como objetivo resumir los esfuerzos de investigación que se han hecho para identificar los principales factores ambientales que afectan la persistencia y transmisión del VIA en aves silvestres acuáticas y cómo estos factores pueden incidir en la prevalencia del virus en estas poblaciones, generando diferencias en la presentación de la infección entre distintas zonas geográficas.

\section{Dinámica de infección del virus IABP en aves silvestres}

En las aves silvestres acuáticas, especialmente las pertenecientes a los órdenes Anseriformes (patos, gansos, cisnes) y Charadriiformes (playeros, gaviotas, gaviotines), se han aislado todos los subtipos descritos de VIA, con la excepción de los subtipos H17N10 y H18N11, solo descritos en murciélagos hasta la fecha (18).

En estos hospederos naturales, el VIA replica preferentemente en el tracto gastrointestinal, excretándose en altas concentraciones a través de las heces. Por lo tanto, la circulación del virus IABP dentro de las poblaciones de aves silvestres, depende de la efectiva transmisión entre estas especies reservorio y los hospederos susceptibles, principalmente a través de la ruta fecal-oral (5). Sin embargo, la prevalencia y la dinámica de infección del virus IABP en las aves silvestres puede variar dependiendo de la locación geográfica, estación del año y especie de ave (7).

En las aves acuáticas de Norteamérica y Europa, la prevalencia del VIA es más alta cuando un gran número de aves de diferentes edades y procedencias se congregan en sus lugares de reproducción, y en donde además existen muchos individuos jóvenes inmunológicamente inmaduros. En estas áreas, la prevalencia puede alcanzar un pico de un $30 \%$ hacia fines del verano/comienzos de otoño, previo a la migración, seguido de una baja durante el invierno $(7,12)$. En cambio en el hemisferio sur, aunque la dinámica de presentación del virus ha sido menos estudiada, investigaciones realizadas en Australia y en África han demostrado que no existe un patrón de presentación estacional marcado, sugiriendo que los factores que inciden en la dinámica de infección en estas áreas son distintos a los del hemisferio norte $(11,19,20)$.

En África tropical, por ejemplo, la dinámica de infección del VIA en aves silvestres muestra una prevalencia baja pero constante durante todo el año $(11,17)$ lo que se podría explicar porque el periodo de reproducción de las aves acuáticas es más extendido que en el hemisferio norte, existiendo individuos inmunológicamente inmaduros durante todo el año, los cuales podrían perpetuar la infección (11). Situación diferente a la encontrada en un estudio de 
vigilancia de VIA en aves silvestres realizado en Chile entre los años 2012 y 2015, en donde se observó una diferencia en la prevalencia entre estaciones, siendo mayor durante los meses de verano/otoño que en invierno/primavera (21).

Aunque estas diferencias geográficas se pueden atribuir a factores relacionados con los hospederos, tales como: especies presentes, conducta de alimentación, uso de hábitats, patrón migratorio, tamaño de la población y congregación estacional entre otros; las condiciones ambientales y la estructura del paisaje en diferentes contextos geográficos pueden tener un papel preponderante en la dinámica de infección del virus en estas poblaciones $(11,22)$.

De acuerdo a investigaciones realizadas utilizando modelos matemáticos, la persistencia del virus en los ambientes acuáticos sería fundamental para el mantenimiento y la circulación del virus en las aves silvestres (23-25). Esto se debe a que las aves infectadas eliminan grandes concentraciones de viriones al ambiente a través de las heces, los cuales pueden sobrevivir en agua por largos periodos de tiempo, siendo ingeridos por un hospedero susceptible, manteniendo la infección dentro de la población mediante la ruta de transmisión fecal-oral (25). La importancia de este mecanismo de transmisión estaría influenciada por el tamaño de la población. De esta forma, en poblaciones grandes, donde existe mayor densidad de individuos y mayor tasa de contacto entre ellos, la transmisión por contacto directo sería más relevante que la ambiental. En cambio en poblaciones de tamaño pequeño, la transmisión ambiental tiene un rol clave en la mantención del virus dentro la comunidad de aves (23).

Por lo tanto, es importante enfatizar el papel que tiene el ambiente como un factor determinante en la epidemiología del VIA en aves silvestres y la necesidad de considerar los factores ecológicos y ambientales en los estudios de prevalencia (25).

\section{Persistencia del virus influenza en los ambientes acuáticos}

Dentro de los factores ambientales que favorecen la persistencia y circulación del virus influenza en los ecosistemas acuáticos, se incluyen elementos tanto bióticos como abióticos y en donde el agua superficial cumple un rol fundamental (8). Así lo han demostrado numerosos estudios en los que se ha determinado que el virus puede sobrevivir en agua por largos períodos de tiempo (Tabla 1).

Tabla1. Persistencia del virus influenza en agua según diversos estudios realizados.

\begin{tabular}{|c|c|c|c|c|c|c|}
\hline \multirow{2}{*}{ Estudio } & \multirow{2}{*}{ Año } & \multirow{2}{*}{ País } & \multicolumn{4}{|c|}{ Persistencia del VIA de acuerdo a distintos parámetros evaluados } \\
\hline & & & $\mathbf{T}^{\mathbf{0}}$ & pH & Salinidad & Otros \\
\hline Webster et al & 1978 & USA & $\begin{array}{l}\text { - } 4 \text { días a } 22^{\circ} \mathrm{C} \\
\text { - más de } 30 \text { días a } 0^{\circ} \mathrm{C}\end{array}$ & --- & --- & --- \\
\hline Stallknecht et al & | 1990 & USA & $\begin{array}{l}-100 \text { días a } 17^{\circ} \mathrm{C} \\
\text {-9 días a } 28^{\circ} \mathrm{C}\end{array}$ & $\begin{array}{l}\text {-100 días a } \mathrm{pH} \\
8.2\end{array}$ & $\begin{array}{l}\text {-100 días a } 0 \text { partes } \\
\text { por trillón ( } \mathrm{ppt}) \\
\text {-9 días a } 20 \mathrm{ppt}\end{array}$ & --- \\
\hline Brown et al & 2009 & USA & $\begin{array}{c}\text { Estable a bajas } \\
\text { temperaturas }\left(<17^{\circ} \mathrm{C}\right)\end{array}$ & $\begin{array}{l}\text { Estable entre } \\
7.4-8.2\end{array}$ & $\begin{array}{l}\text { Estable entre } \\
0-20000 \text { partes por } \\
\text { millón (ppm) }\end{array}$ & --- \\
\hline Nazir et al & 2010 & Alemania & $\begin{array}{c}\text {-Días entre } 30 \text { y } 20^{\circ} \mathrm{C} \\
\text {-Semanas a } 10^{\circ} \mathrm{C} \\
\text { - Meses entre } 0^{\circ} \mathrm{C} \text { y }-10^{\circ} \mathrm{C}\end{array}$ & --- & --- & $\begin{array}{l}\text { Agua destilada: alta persistencia } \\
\text { (hasta } 642 \text { días) } \\
\text { Solución salina normal: menor } \\
\text { persistencia (hasta } 321 \text { días) } \\
\text { Agua superficial: persistencia } \\
\text { más baja (hasta } 55 \text { días) }\end{array}$ \\
\hline $\begin{array}{l}\text { Lebarbenchon } \\
\text { et al }\end{array}$ & 2011 & USA & Estable entre $17^{\circ} \mathrm{C}$ y $23^{\circ} \mathrm{C}$ & Estable a 7.2 & --- & --- \\
\hline Keeler et al & 2013 & USA & $\begin{array}{l}\text { Todos los virus se } \\
\text { evaluaron a } 17^{\circ} \mathrm{C}\end{array}$ & --- & --- & $\begin{array}{l}\text { Agua destilada: alta persistencia } \\
\text { (más de } 80 \text { días) } \\
\text { Agua superficial filtrada: } \\
\text { menor persistencia (hasta } 60 \text { días) } \\
\text { Agua superficial intacta: } \\
\text { persistencia más baja (menos de } \\
20 \text { días) }\end{array}$ \\
\hline Keeler et al & 2014 & USA & $\begin{array}{l}\text { Alta viabilidad en bajas } \\
\text { temperaturas }\left(<17^{\circ} \mathrm{C}\right)\end{array}$ & $\begin{array}{l}\text { Estable entre } \\
\quad 7.0-8.5\end{array}$ & Estable a 0.5 ppt & $\begin{array}{c}\text { Estable a bajas } \\
\text { concentraciones de amoniaco } \\
(<0.5 \mathrm{mg} / \mathrm{L})\end{array}$ \\
\hline
\end{tabular}


En 1978, Webster et al (26) publican la primera información relacionada con la persistencia del VIA en los ambientes acuáticos utilizando un virus A/Duck/Memphis/546/74 (H3N2), comprobando que puede permanecer infectivo en aguas de lagos hasta 4 días a $22^{\circ} \mathrm{C}$ y más de 30 días a $0^{\circ} \mathrm{C}$. Estudios posteriores, realizados bajo condiciones de laboratorio, han demostrado que la persistencia del virus en agua puede variar ampliamente desde pocos días hasta varios meses, dependiendo de la cepa viral y de las características del agua (temperatura, $\mathrm{pH}$ y salinidad) $(9,27)$.

Estos estudios, utilizando un modelo de agua destilada modificada, determinaron que bajas temperaturas $\left(4 \mathrm{a} 17^{\circ} \mathrm{C}\right), \mathrm{pH}$ neutro a básico (7.08.5) y baja salinidad ( $<20000 \mathrm{ppm}$ ) favorecen la persistencia del VIA en el agua, mientras que condiciones ácidas $(\mathrm{pH}<6.6)$, temperaturas cálidas $\left(>32^{\circ} \mathrm{C}\right)$ y alta salinidad (>25000 ppm), la reducen significativamente. Posteriormente, Lebarbenchon et al (28) encontraron resultados similares al evaluar dos subtipos virales (H4N6 y H3N8) aislados desde patos en Estados Unidos. Ambos virus persistieron durante varios meses en agua destilada a temperaturas constantes (ente 17 y $23^{\circ} \mathrm{C}$ ) y a $\mathrm{pH}$ neutro.

En otro estudio realizado por Nazir et al (29), se evaluó la persistencia de tres cepas de virus IABP (H4N6, H5N1 y H6N8) bajo cinco diferentes temperaturas y en aguas con distintas propiedades fisicoquímicas (agua destilada, solución salina normal y agua obtenida de la superficie del Lago de Constanza). La persistencia de los virus fue mayor en agua destilada, seguida por una solución salina normal. En agua superficial tuvieron una menor persistencia. Además, los resultados mostraron que el tiempo de supervivencia de los virus fue inversamente proporcional a la temperatura, permaneciendo infecciosos por pocos días a temperaturas entre 30 y $20^{\circ} \mathrm{C}$ y durante meses a temperaturas entre $0^{\circ} \mathrm{C}$ y $-10^{\circ} \mathrm{C}$. Situación que se condice con lo reportado por Keeler et al (30), en donde la persistencia del virus fue mayor en el agua destilada (más de 80 días) y notablemente menor en el agua superficial intacta (menos de 20 días).

Es importante destacar que todos los estudios antes mencionados fueron realizados bajo condiciones de laboratorio, utilizando agua destilada modificada para obtener distintos parámetros fisicoquímicos. Un estudio realizado bajo condiciones más semejantes a lo que ocurre en los cuerpos de agua naturales, fue realizado por Keeler et al (31) quién utilizó muestras de aguas superficiales recolectadas desde 38 hábitats de aves acuáticas en Estados Unidos, para evaluar la persistencia de distintos subtipos de virus, encontrando resultados similares a los descritos anteriormente y demostrando además que bajas concentraciones de amoniaco $(<0.5 \mathrm{mg} / \mathrm{L})$ igualmente favorecen la persistencia del virus.

Por su parte, Shoham et al (32) también evaluaron la persistencia de diversos subtipos de VIA en agua ambiental congelada artificialmente, la mayoría de los cuales fueron estables a lo largo de un año en un rango de temperaturas -20 y $-30^{\circ} \mathrm{C}$, sugiriendo que las regiones árticas podrían representar un importante reservorio ambiental del virus para las poblaciones de aves silvestres.

No obstante, debido a que en los cuerpos de agua naturales existen otras variables que pueden interactuar con las anteriormente mencionadas, es importante implementar la aplicabilidad de futuros estudios bajo condiciones de campo, considerando factores como: variaciones de temperatura entre el día y la noche; caudal del agua y profundidad; exposición a rayos UV; turbidez; adherencia del VIA a sustratos orgánicos e inorgánicos presentes en el agua y diversidad biológica (bacterias, biofilms, organismos filtradores y otros invertebrados) entre otras $(8,33)$. La diversidad biológica ha sido considerada como relevante en algunos estudios, puesto que se ha determinado que la comunidad biótica presente en el agua tendría un rol importante en la concentración y/o inactivación del virus en el ambiente (34).

\section{Efecto de los factores ambientales sobre la prevalencia del VIA en aves silvestres.}

La investigación empírica de los factores ambientales y ecológicos que influyen en la dinámica de presentación del VIA en aves silvestres aún está en pleno desarrollo $(10,11,13,14)$. No obstante, estudios realizados hasta el momento concuerdan en aquellos que podrían tener un importante rol sobre la prevalencia del VIA en los ecosistemas, dentro de los cuales se describen elementos abióticos; como precipitaciones y temperatura; bióticos, como especies de aves presentes y cantidad de vegetación; y factores antropogénicos, como el uso de la tierra y tipo de cobertura de suelo $(15,19,22)$.

La temperatura, las precipitaciones y la cobertura vegetacional medida a través del Índice 
Diferencial de Vegetación Normalizado (NDVI), se han identificado como factores ambientales claves relacionados con la ocurrencia de brotes de IAAP H5N1 en Europa (10). El NDVI es el índice más utilizado para la detección remota de vegetación, el cual estima la cantidad de masa fotosintética a partir de la intensidad de la radiación de ciertas bandas del espectro electromagnético que la vegetación emite. Valores elevados de NDVI, bajas precipitaciones y un aumento de las temperaturas mínimas durante la estación fría demostraron estar relacionadas con brotes de IAAP, probablemente debido a que un aumento del NDVI en combinación con un aumento de las temperaturas mínimas durante el invierno, proporciona una mayor disposición de alimento y refugio para las aves en temporadas frías, favoreciendo una mayor congregación y, por lo tanto, un mayor riesgo de transmisión de patógenos (10).

Algo similar se observó en África y Medio Oriente, en donde la ocurrencia de IAAP H5N1 ha sido asociada con niveles altos de NDVI y ha estado prácticamente ausente en áreas con bajo NDVI, indicando que la distribución espacial de los casos de IAAP H5N1 en estas zonas estaría relacionada con características ambientales específicas, generando una "huella digital ambiental" para la presentación del virus (35).

Investigaciones realizadas en Norteamérica también indican a la temperatura como un factor importante que influye en la prevalencia de virus IABP en aves silvestres, asociando una mayor probabilidad de infección con bajas temperaturas $(15,36,37)$. Situación que se condice con un modelo predictivo realizado por Herrick et al (38), en donde se identifica a la temperatura y las precipitaciones como importantes predictores para brotes de VIA en aves silvestres. Regiones con baja precipitación anual y bajas temperaturas fueron indicadas como nicho ambiental primario para el riesgo de brotes de VIA en aves silvestres, recalcando la importancia de las regiones boreales en la epidemiología del virus. En regiones de clima Mediterráneo, las temperaturas bajas y pocas precipitaciones también han sido asociadas con una prevalencia mayor de VIA en aves silvestres (13).

Por el contrario, investigaciones realizadas en Australia y en regiones tropicales de África, indican que la temperatura no tendría mayor influencia en la prevalencia de VIA en aves silvestres, sugiriendo que existen otros factores que influyen en la presentación del virus en estas regiones $(11,16,19)$. Gaidet et al (11) utilizaron un conjunto de datos obtenidos en humedales de 15 países africanos para evaluar la influencia de un amplio rango de factores ecológicos en la prevalencia de VIA en aves silvestres.

En este estudio se determinó que las variaciones en la prevalencia estuvieron relacionadas con factores ecológicos del hospedero más que con condiciones de temperatura, estando positivamente asociada con la densidad de aves en los humedales y con el arribo de migrantes desde Eurasia. Las variables climáticas (temperatura y humedad), por el contrario, fueron pobremente relacionadas a la prevalencia. Esto difiere de lo encontrado en regiones boreales, puesto que las regiones afro-tropicales se caracterizan por tener temperaturas mayores o iguales a $20^{\circ} \mathrm{C}$ durante todo el año, lo que no es favorable para el mantenimiento del virus en el ambiente, indicando que en estas áreas la transmisión por contacto directo tendría mayor relevancia que la ambiental para el mantenimiento de la infección en las poblaciones (16).

Estos resultados son similares a otros encontrados en el continente africano, en donde un incremento en la prevalencia estuvo relacionado con la temporada de arribo de migrantes $(17,39)$. Además, Fuller et al (39) también determinó que las temporadas Iluviosas estarían asociadas con un incremento en la prevalencia de VIA en humedales de África Central. Probablemente esto se deba a dos mecanismos: [1] que las precipitaciones desencadenan un aumento en la disponibilidad de alimentos $y$, por lo tanto, una mayor abundancia de aves y [2] que el inicio de la temporada lluviosa coincide con el inicio del periodo de reproducción de las aves, lo que favorece la congregación en los sitios aumentando la tasa de contacto.

Basados en estos resultados, los autores sugieren que las precipitaciones determinarían una oportunidad de reproducción, influenciando la estructura etaria dentro de la población (mayor cantidad de juveniles), lo que afecta la dinámica de infección del VIA (39). Esto es consistente con lo reportado por Van Dijk et al (12), quienes demostraron que el pico de prevalencia de VIA en Patos de collar (Anas platyrhynchos) en Holanda, estuvo relacionado con un aumento de los individuos jóvenes susceptibles durante fines de verano/principios de otoño. Época que coincide con el tiempo de arribo de migrantes, proporcionando una fuerte evidencia del rol que tendrían las aves migratorias como diseminadores en las epidemias estacionales de virus IABP en aves silvestres 
En un estudio realizado en el sudeste de Australia (19), se evaluó la prevalencia de VIA en muestras de heces de patos silvestres y su relación con factores bióticos (número de aves) y abióticos (variables climáticas). Estos resultados también demostraron un efecto positivo de las precipitaciones sobre la prevalencia, tanto en forma inmediata, como a largo plazo producto del fenómeno de oscilación del niño del sur (ENSO). La temperatura, a diferencia del hemisferio norte, no tuvo un efecto significativo en los datos, así como tampoco el número de aves presentes al momento del muestreo, indicando que la dinámica del VIA no es simplemente una función del número de aves en el humedal, sino que una combinación de muchos factores involucrados.

Otra de las investigaciones bajo condiciones de campo que se ha realizado en este contexto, corresponde a un estudio en España en donde se evaluó la influencia de diversos factores ambientales (condiciones climáticas, densidad y diversidad de aves, propiedades físico-químicas del agua y estructura de la vegetación) en la dinámica del VIA en diversos humedales (13). En este estudio las variables explicativas fueron agrupadas en factores. Los resultados determinaron que la combinación de variables espaciales y temporales (locación, año y periodo de muestreo) sería el factor que mayormente explicaría la variación en la prevalencia de VIA a lo largo del periodo de estudio (36.8\%), seguido de las variables meteorológicas $(21.5 \%)$ y finalmente la combinación de la composición de la comunidad de aves silvestres con la estructura de la vegetación (21.1\%).

Aunque estos resultados son similares a los encontrados en otras regiones del hemisferio norte, es importante destacar que ninguna de las variables incluidas en el factor "características físico-químicas del agua" fue retenida en el modelo final, probablemente debido a que en condiciones de campo existen otras variables como el efecto de la dilución y otros factores bióticos, que podrían haber sido potencialmente más importantes que el grado de variación de las propiedades físicas evaluadas (8).

Factores antropogénicos relacionados con el uso de la tierra agrícola, también han sido indicados como importantes en la presentación de VIA. Estudios ya han determinado que existe una fuerte asociación entre brotes de IAAP H5N1 y zonas de cultivo intensivo de arroz en Asia, debido a una gran congregación de patos domésticos que forrajean en los arrozales, correspondiendo a un factor crítico en la persistencia y propagación de la IAAP en ese continente $(40,41,42)$.

Algo similar fue encontrado en Madagascar, en donde se combinaron datos serológicos de aves de corral con factores ambientales obtenidos por teledetección. En este estudio, la seroprevalencia de virus IABP fue mayor en granjas vecinas a cultivos de arroz y humedales que en aquellas rodeadas por paisaje de sabana, reafirmando el rol de los ecosistemas compuestos por campos de arroz y altas densidades de patos en la epidemiología del virus (43). De la misma forma en los humedales, el uso de tierra agrícola cercano a ellos favorecería la agregación de las aves silvestres en busca de alimento, aumentando la tasa de contacto entre los individuos, creando las condiciones ideales para la transmisión del virus (10). Así fue determinado en un estudio realizado en Estados Unidos en donde se realizó un mapa de riesgo de VIA en aves silvestres y en donde la cantidad de tierra cultivada en cada condado tuvo una relación significativa con la prevalencia de VIA en las aves (36).

Además, el cambio en el uso de la tierra producto de una agricultura intensiva, ha provocado una fragmentación y pérdida de humedales alterando las poblaciones de aves silvestres. Muchas especies, han disminuido su población, mientras que otras se han adaptado a los paisajes alterados por el hombre, provocando una mayor densidad de aves en los sitios, estrés y proximidad a aves domésticas, favoreciendo la transmisión del virus dentro de las bandadas y entre especies diferentes (44).

A lo anterior, también se le debe sumar el cambio climático, el cual puede provocar alteraciones importantes en la ecología del VIA. Un aumento en las temperaturas puede potencialmente afectar los patrones migratorios, creando nuevos ensambles de aves y por lo tanto, generando nuevas oportunidades para el transporte del VIA y el reordenamiento de genes virales (45). Además, cambios en el clima podrían modificar la supervivencia del virus en el medio ambiente. La temperatura del agua y sus características fisicoquímicas ( $\mathrm{pH}$ y salinidad), también pueden verse alteradas, dando como resultado un aumento en la persistencia viral, la patogenicidad y la transmisibilidad $(44,45)$.

No obstante, predecir los impactos del cambio climático en la ecología del VIA requerirá de 
modelos y estrategias de investigación que incluyan la interacción de diversas variables; como la supervivencia del virus en el ambiente, el cambio en el uso de la tierra, la existencia de humedales más pequeños, mayor densidad de aves y aumento de tasas de contacto, entre otras $(44,45)$. La mejor comprensión de las influencias climáticas sobre la ecología del virus será fundamental para mejorar las estrategias de prevención y de vigilancia de VIA a nivel global.

En conclusión, a pesar del esfuerzo considerable realizado a nivel mundial para la vigilancia del VIA en aves silvestres, la información existente acerca de la ecología del virus y los factores ambientales que favorecen su presentación en estas poblaciones, continúa siendo muy escasa.

La investigación realizada hasta ahora acerca del VIA se ha enfocado principalmente en la identificación y caracterización de los subtipos, centrándose en la supervivencia y la transmisión viral en condiciones de laboratorio o a través de modelos matemáticos. Sin embargo, muy pocos estudios han profundizado en la relación entre el patrón de ocurrencia y factores ambientales bajo condiciones de campo. Además, este escaso conocimiento empírico es derivado principalmente desde estudios realizados en el hemisferio Norte y en algunas regiones de África, por lo tanto, no podría ser extrapolado directamente a regiones del hemisferio sur, donde existen diferencias en los hospederos, en factores climáticos y en la estacionalidad.
Hasta la fecha en Sudamérica no existen estudios que exploren los factores ecológicos y ambientales relacionados con la presentación de VIA en aves silvestres, a pesar de que se ha descrito una amplia diversidad de subtipos que circulan en la región, tanto de origen Norteamericano como linajes que son exclusivos para Sudamérica $(21,46-48)$. De esta manera, resultaría interesante generar información con respecto a la dinámica de presentación del virus y los factores ambientales involucrados a nivel local. Para esto, es necesario mejorar las investigaciones a nivel de campo y realizar estudios de prevalencia que incluyan factores ecológicos y ambientales en distintos contextos geográficos. Esto permitiría evaluar de mejor forma el riesgo asociado con la transmisión del virus desde los reservorios de vida silvestre hacia animales domésticos, mejorando los programas de vigilancia y dirigiendo los esfuerzos de muestreo hacia hábitats y temporadas que son más favorables para el mantenimiento y transmisión viral.

\section{Agradecimientos}

Esta investigación fue financiada por ANID Programa Becas de Doctorado No 21150579, Fondecyt 1191747 a CHW y Fondecyt 11190755 a PJB

\section{REFERENCIAS}

1. Taubenberger JK, Morens DM. Pandemic influenza - including a risk assessment of H5N1. OIE Rev Sci Tech. 2009; 28(1):187202. https://www.ncbi.nlm.nih.gov/pmc/ articles/PMC2720801

2. Smith GJD, Vijaykrishna D, Bahl J, Lycett SJ, Worobey M, Pybus OG, et al. Origins and evolutionary genomics of the 2009 swineorigin H1N1 influenza a epidemic. Nature. 2009; 459(7250):1122-1125. https://www. nature.com/articles/nature 08182
3. De Vries E, Guo H, Dai M, Rottier PJM, Van Kuppeveld FJM, De Haan CAM. Rapid emergence of highly pathogenic avian influenza subtypes from a subtype H5N1 hemagglutinin variant. Emerg Infect Dis. 2015; 21(5):842-846. https://www.ncbi. nlm.nih.gov/pubmed/25897518

4. Capua I, Alexander DJ. Avian influenza infection in birds: A challenge and opportunity for the poultry veterinarian. Poult Sci. 2009; 88(4):842-846. https://academic.oup.com/ ps/article-lookup/doi/10.3382/ps.2008-00289 
5. Yoon SW, Webby RJ, Webster RG. Evolution and ecology of influenza a viruses. In: Current Topics in Microbiology and Immunology. Springer Verlag; 2014. https://doi.org/10.1007/82_2014_396

6. Lee D-H, Torchetti MK, Winker K, Ip HS, Song C-S, Swayne DE. Intercontinental Spread of Asian-Origin H5N8 to North America through Beringia by Migratory Birds. J Virol. 2015; 89(12):6521-6524. https://jvi.asm.org/ content/89/12/6521.short

7. Munster VJ, Fouchier RAM. Avian influenza virus: Of virus and bird ecology. Vaccine. 2009; 27(45):6340-6444. https://www. sciencedirect.com/science/article/pii/ $\underline{\text { S0264410X09003740 }}$

8. Stallknecht DE, Goekjian VH, Wilcox BR, Poulson RL, Brown JD. Avian Influenza Virus in Aquatic Habitats: What Do We Need to Learn? Avian Dis Dig. 2010; 5(s1):e99-100. https://www.aaapjournals. info/doi/abs/10.1637/8760-033109-Reg.1

9. Brown JD, Goekjian G, Poulson R, Valeika $S$, Stallknecht DE. Avian influenza virus in water: Infectivity is dependent on $\mathrm{pH}$, salinity and temperature. Vet Microbiol. 2009; 136(1-2):20-26. https://www. sciencedirect.com/science/article/pii/ $\underline{\text { S0378113508004884 }}$

10. Si Y, Wang T, Skidmore AK, de Boer WF, Li L, Prins HHT. Environmental factors influencing the spread of the highly pathogenic avian influenza H5N1 virus in wild birds in Europe. Ecol Soc. 2010; 15(3):26. https://www. ecologyandsociety.org/vol15/iss3/art26/

11. Gaidet N, Caron A, Cappelle J, Cumming GS, Balança G, Hammoumi S, et al. Understanding the ecological drivers of avian influenza virus infection in wildfowl: A continental-scale study across Africa. Proc R Soc B Biol Sci. 2012; 279(1731):11311141. https://royalsocietypublishing.org/ doi/full/10.1098/rspb.2011.1417

12. Dijk JGB van, Hoye BJ, Verhagen $\mathrm{JH}$, Nolet $B A$, Fouchier RAM, Klaassen M. Juveniles and migrants as drivers for seasonal epizootics of avian influenza virus. J Anim Ecol. 2014; 83(1):266-275. https:// besjournals.onlinelibrary.wiley.com/doi/ abs/10.1111/1365-2656.12131
13. Pérez-Ramírez $E$, Acevedo $P$, Allepuz A, Gerrikagoitia X, Alba A, Busquets N, et al. Ecological Factors Driving Avian Influenza Virus Dynamics in Spanish Wetland Ecosystems. PLoS One. 2012; 7(11):e46418. https://dx.plos.org/10.1371/ journal.pone.0046418

14. Torrontegi O, Alvarez $\mathrm{V}$, Acevedo $\mathrm{P}$, Gerrikagoitia X, Höfle U, Barral M. Longterm avian influenza virus epidemiology in a small Spanish wetland ecosystem is driven by the breeding Anseriformes community. Vet Res. 2019; 50(1):4. https:// veterinaryresearch.biomedcentral.com/ articles/10.1186/s13567-019-0623-5

15. Farnsworth $M L$, Miller RS, Pedersen $K$, Lutman MW, Swafford SR, Riggs PD, et al. Environmental and demographic determinants of avian influenza viruses in waterfowl across the contiguous United States. PLoS One. 2012; 7(3). https://journals.plos.org/plosone/ article?id=10.1371/journal.pone.0032729

16. Gaidet N. Ecology of Avian Influenza Virus in Wild Birds in Tropical Africa. Avian Dis. 2016; 60(1s):296-301. https://www. aaapjournals.info/doi/abs/10.1637/11149$\underline{051115-R e v i e w}$

17. Caron A, Abolnik C, Mundava J, Gaidet N, Burger CE, Mochotlhoane B, et al. Persistence of low pathogenic avian influenza virus in waterfowl in a southern African ecosystem. Ecohealth.2011; 8(1):109-115. https:// link.springer.com/article/10.1007/s10393$\underline{010-0356-4}$

18. Tong S, Zhu X, Li Y, Shi M, Zhang J, Bourgeois $M$, et al. New World Bats Harbor Diverse Influenza A Viruses. PLoS Pathog. 2013; 9(10). https://journals.plos.org/ plospathogens/article?id=10.1371/journal. ppat. 1003657

19. Ferenczi M, Beckmann C, Warner S, Loyn $R$, O'Riley $K$, Wang $X$, et al. Avian influenza infection dynamics under variable climatic conditions, viral prevalence is rainfall driven in waterfowl from temperate, south-east Australia. Vet Res. 2016; 47(1):23. http://www.veterinaryresearch. org/content/47/1/23 
20. Mundava J, Caron A, Garine Wichatitsky $M$, Abolnik C, Mundy P, Gaidet N. The role of breeding phenology and aggregation of waterfowl on avian influenza dynamics in southern Africa. Ibis. 2016;158(4):762775. https://onlinelibrary.wiley.com/doi/ abs/10.1111/ibi.12404

21. Jiménez-Bluhm $P$, Karlsson $E A$, Freiden $P$, Sharp B, Di Pillo F, Osorio JE, et al. Wild birds in Chile Harbor diverse avian influenza A viruses. Emerg Microbes Infect. 2018; 7(1):1-4. https://www.tandfonline.com/ doi/full/10.1038/s41426-018-0046-9

22. Cumming GS, Abolnik C, Caron A, Gaidet N, Grewar J, Hellard E, et al. A social-ecological approach to landscape epidemiology: geographic variation and avian influenza. Landsc Ecol. 2015; 30(6):963-985. https:// link.springer.com/article/10.1007/s10980$\underline{015-0182-8}$

23. Breban R, Drake JM, Stallknecht DE, Rohani P. The Role of Environmental Transmission in Recurrent Avian Influenza Epidemics. PLoS Comput Biol. 2009; 5(4):e1000346. https://journals.plos.org/ploscompbiol/ article?id=10.1371/journal.pcbi. 1000346

24. Rohani P, Breban R, Stallknecht DE, Drake JM. Environmental transmission of low pathogenicity avian influenza viruses and its implications for pathogen invasion. Proc Natl Acad Sci U S A. 2009; 106(25): 10365-10369. https://www.pnas. org/content/106/25/10365. short

25. Roche B, Lebarbenchon C, Gauthier-Clerc M, Chang CM, Thomas F, Renaud F, et al. Waterborne transmission drives avian influenza dynamics in wild birds: The case of the 2005-2006 epidemics in the Camargue area. Infect Genet Evol. 2009; 9(5):800-805. https://www.sciencedirect.com/science/ article/pii/S156713480900077X

26. Webster RG, Yakhno M, Hinshaw VS, Bean WJ, Copal Murti K. Intestinal influenza: Replication and characterization of influenza viruses in ducks. Virology. 1978; 84(2):268278. https://www.sciencedirect.com/ science/article/pii/0042682278902477
27. Stallknecht DE, Brown JD. Tenacity of avian influenza viruses. Rev sci tech Off int Epiz. 2009; 28(1):59-67. https://pdfs. semanticscholar.org/4556/0521cf6246e48 52e1ccffd0936e9fadc80bc.pdf

28. Lebarbenchon $C$, Yang $M$, Keeler SP, Ramakrishnan MA, Brown JD, Stallknecht $\mathrm{DE}$, et al. Viral Replication, Persistence in Water and Genetic Characterization of Two Influenza A Viruses Isolated from Surface Lake Water. PLoS One. 2011; 6(10):e26566. https://dx.plos.org/10.1371/journal. pone. 0026566

29. Nazir J, Haumacher R, Ike A, Stumpf $P$, Böhm R, Marschang RE. Long-Term Study on Tenacity of Avian Influenza Viruses in Water (Distilled Water, Normal Saline, and Surface Water) at Different Temperatures. Avian Dis. 2010; 54(s1):720-724. http:// www.bioone.org/doi/abs/10.1637/8754033109-ResNote.1

30. Keeler SP, Lebarbenchon C, Stallknecht DE. Strain-related variation in the persistence of influenza A virus in three types of water: distilled water, filtered surface water, and intact surface water. Virol J. 2013; 10(1):13. https://virologyj. biomedcentral. com/articles/10.1186/1743-422X-10-13

31. Keeler SP, Dalton MS, Cressler AM, Berghaus RD, Stallknecht DE. Abiotic factors affecting the persistence of avian influenza virus in surface waters of waterfowl habitats. Appl Environ Microbiol. 2014; 80(9):2910-2917. https://aem.asm.org/content/80/9/2910. short

32. Shoham $D$, Jahangir $A$, Ruenphet $S$, Takehara $\mathrm{K}$. Persistence of Avian Influenza Viruses in Various Artificially Frozen Environmental Water Types. Influenza Res Treat. 2012; 2012:1-11. https://www.hindawi.com/ journals/irt/2012/912326/abs/

33. Dalziel AE, Delean $S$, Heinrich $S$, Cassey P. Persistence of Low Pathogenic Influenza A Virus in Water: A Systematic Review and Quantitative Meta-Analysis. PLoS One 2016; 11(10):e0161929. https://dx.plos. org/10.1371/journal.pone.0161929 
34. Meixell BW, Borchardt MA, Spencer SK. Accumulation and inactivation of avian influenza virus by the filter-feeding invertebrate Daphnia magna. Appl Environ Microbiol. 2013; 79(23):7249-7255. https:// aem.asm.org/content/79/23/7249.short

35. Williams RA, Peterson AT. Ecology and geography of avian influenza (HPAI H5N1) transmission in the Middle East and northeastern Africa. Int J Health Geogr. 2009; 8(1):47. http://ij-healthgeographics. biomedcentral.com/articles/10.1186/1476$\underline{072 X-8-47}$

36. Fuller TL, Saatchi SS, Curd EE, Toffelmier E, Thomassen HA, Buermann W, et al. Mapping the risk of avian influenza in wild birds in the US. BMC Infect Dis. 2010; 10(1):187. https://bmcinfectdis.biomedcentral.com/ articles/10.1186/1471-2334-10-187

37. Papp Z, Clark RG, Parmley EJ, Leighton FA, Waldner C, Soos C. The ecology of avian influenza viruses in wild dabbling ducks (Anas spp.) in Canada. PLoS One. 2017; 12(5):e0176297. https://dx.plos. org/10.1371/journal.pone.0176297

38. Herrick KA, Huettmann $F$, Lindgren MA. A global model of avian influenza prediction in wild birds: the importance of northern regions. Vet Res. 2013; 44(1):42. http://www. veterinaryresearch.org/ content/44/1/42

39. Fuller TL, Ducatez MF, Njabo KY, CouacyHymann E, Chasar T, Aplogan GL, et al. Seasonality dynamics of avian influenza occurrences in Central and West Africa. bioRxiv. 2014; 007740. https://www. biorxiv.org/content/10.1101/007740v1. abstract

40. Tiensin T, Ahmed SSU, Rojanasthien S, Songserm T, Ratanakorn P, Chaichoun K, et al. Ecologic Risk Factor Investigation of Clusters of Avian Influenza A (H5N1) Virus Infection in Thailand. J Infect Dis. 2009; 199(12):1735-1743. https://academic.oup. com/jid/article-lookup/doi/10.1086/599207

41. Gilbert M, Newman SH, Takekawa JY, Loth L, Biradar C, Prosser DJ, et al. Flying over an infected landscape: Distribution of highly pathogenic avian influenza H5N1 risk in South Asia and satellite tracking of wild waterfowl. Ecohealth. 2010; 7(4):448-458. https://link.springer.com/article/10.1007/ s10393-010-0672-8

42. Paul M, Tavornpanich S, Abrial D, Gasqui P, Charras-Garrido M, Thanapongtharm W, et al. Anthropogenic factors and the risk of highly pathogenic avian influenza H5N1: prospects from a spatial-based model. Vet Res. 2010; 41(3):28. http://www.vetres. org/10.1051/vetres/2009076

43. Guerrini L, Paul MC, Leger $L$, Andriamanivo HR, Maminiaina OF, Jourdan $M$, et al. Landscape attributes driving avian influenza virus circulation in the Lake Alaotra region of Madagascar. Geospat Health. 2014; 8(2):445-453. https://geospatialhealth. net/index.php/gh/article/view/33

44. Vandegrift KJ, Sokolow SH, Daszak P, Kilpatrick AM. Ecology of avian influenza viruses in a changing world. Ann N Y Acad Sci. 2010; 1195:113-128. https://www.ncbi. nlm.nih.gov/pmc/articles/PMC2981064/

45. Morin CW, Stoner-Duncan B, Winker K, Scotch M, Hess JJ, Meschke JS, et al. Avian influenza virus ecology and evolution through a climatic lens. Environ Int. 2018;119:241249. https://www.sciencedirect.com/ science/article/pii/S0160412018302629

46. de Araujo J, de Azevedo Júnior SM, Gaidet N, Hurtado RF, Walker D, Thomazelli LM, et al. Avian Influenza Virus (H11N9) in Migratory Shorebirds Wintering in the Amazon Region, Brazil. PLoS One. 2014; 9(10):e110141. http://dx.plos.org/10.1371/journal. pone. 0110141

47. Xu K, Ferreri L, Rimondi A, Olivera V, Romano $M$, Ferreyra $\mathrm{H}$, et al. Isolation and characterization of an H9N2 influenza virus isolated in Argentina. Virus Res. 2012; 168(1-2):41-47. https://www. sciencedirect.com/science/article/abs/pii/ $\underline{\text { S0168170212002079 }}$

48. Rimondi A, Xu K, Craig MI, Shao H, Ferreyra $H$, Rago M V., et al. Phylogenetic Analysis of H6 Influenza Viruses Isolated from Rosy-Billed Pochards (Netta peposaca) in Argentina Reveals the Presence of Different HA Gene Clusters. J Virol. 2011; 85(24):13354-13362. https://jvi.asm.org/ content/85/24/13354.short 